\title{
Blood Transfusion Strategies in Patients Undergoing Extracorporeal Membrane Oxygenation
}

\author{
Hyoung Soo Kim ${ }^{1}$, and Sunghoon Park ${ }^{2}$ \\ ${ }^{1}$ Department of Cardiothoracic Surgery, ${ }^{2}$ Division of Pulmonary, Allergy and Critical Care Medicine, Department of Internal Medicine, \\ Hallym University Sacred Heart Hospital, Anyang, Korea
}

Extracorporeal membrane oxygenation (ECMO) is frequently associated with bleeding and coagulopathy complications, which may lead to the need for transfusion of multiple blood products. However, blood transfusions are known to increase morbidity and mortality, as well as hospital cost, in critically ill patients. In current practice, patients on ECMO receive a transfusion, on average, of 1-5 packed red blood cells (RBCs)/day, with platelet transfusion accounting for the largest portion of transfusion volume. Generally, adult patients require more transfusions than neonates or children, and patients receiving venovenous ECMO for respiratory failure tend to need smaller transfusion volumes compared to those receiving venoarterial ECMO for cardiac failure. Observation studies have reported that a higher transfusion volume was associated with increased mortality. To date, the evidence for transfusion in patients undergoing ECMO is limited; most knowledge on transfusion strategies was extrapolated from studies in critically ill patients. However, current data support a restrictive blood transfusion strategy for ECMO patients, and a low transfusion trigger seems to be safe and reasonable.

Key Words: blood transfusion; extracorporeal membrane oxygenation.

\section{Introduction}

Extracorporeal membrane oxygenation (ECMO) is now increasingly used around the world [1]. However, the management of hemoglobin levels and transfusion of blood products in patients receiving ECMO is still a subject of debate. Although the Extracorporeal Life Support Organization (ELSO) recommends maintaining hemoglobin levels within the normal range (12-14 g/dL) during ECMO [1], these guidelines are not evidence-based. In addition, modern ECMO systems are more biocompatible, and associated with less hemolysis and fewer bleeding complications, compared to those in the early ECMO era, further reducing the need for transfusion.

Blood transfusions are well known to be associated with adverse effects, such as infections and immune-mediated reactions (Table 1) [2,3]. As randomized controlled trials have shown benefit of reducing transfusions [4,5], current guidelines on red blood cell (RBC) transfusion advise a restrictive strategy in critically ill patients. Accordingly, patients on ECMO may also benefit from the restrictive strategy that does not require maintaining hemoglobin levels

\footnotetext{
Received on December 5, 2016 Revised on January 30, 2017 Accepted on February 6, 2017

Correspondence to: Sunghoon Park, Division of Pulmonary, Allergy and Critical Care Medicine, Department of Internal Medicine, Hallym University Sacred Heart Hospital,

22 Gwanpyeong-ro 170beon-gil, Dongan-gu, Anyang 14068, Korea

Tel: +82-31-380-3715, Fax: +82-31-380-3973, E-mail: f2000tj@naver.com
}

*No potential conflict of interest relevant to this article was reported.

(c) This is an Open Access article distributed under the terms of the Creative Commons Attribution Non-Commercial License (http://creativecommons.org/ licenses/by-nc/4.0/) which permits unrestricted non-commercial use, distribution, and reproduction in any medium, provided the original work is properly cited. Copyright (c) 2017 The Korean Society of Critical Care Medicine 
Table 1. Transfusion-related adverse events

\begin{tabular}{lll}
\hline \multirow{2}{*}{ Infectious AEs } & \multicolumn{1}{c}{ Immune-mediated } & Noninfectious AEs \\
\cline { 2 - 3 } & \multicolumn{1}{c}{ Nonimmune-mediated } \\
\hline Human immunodeficiency virus (HIV) & Acute hemolytic transfusion reaction & Transfusion-associated circulatory overload (TACO) \\
Hepatitis B virus & Febrile nonhemolytic reaction & Air embolism \\
Hepatitis C virus & Anaphylactic reaction & Nonimmune hemolysis \\
Human T cell lymphotrophic virus (HTLV) & Transfusion-related acute lung injury (TRALI) & Iron overload \\
Bacterial infection & Alloimmunization to RBC antigens, platelets, and leukocytes (HLA) & \\
& Transfusion associated graft versus host disease (GVHD) & \\
\hline & Delayed hemolytic transfusion reaction & \\
\hline
\end{tabular}

AE: adverse events; HLA: human leukocyte antigen.

within the normal range. Moreover, while the primary aim of RBC transfusion is to increase oxygen delivery $\left(\mathrm{DO}_{2}\right)$, an increase in $\mathrm{DO}_{2}$ is not always followed by an increase in oxygen uptake $\left(\mathrm{VO}_{2}\right)[2,6]$. Therefore, unless patients experience severe bleeding, the beneficial effect of transfusions on oxygenation may be small. Regarding platelet transfusions, like other blood components, they can cause various transfusion reactions and be associated with increased risk of multiple donor exposures [7].

In the present article, we aimed to review the current transfusion practice and introduce the existing evidence on transfusion strategies for patients undergoing ECMO.

\section{Adverse Effects of Stored RBCs}

Packed RBCs can be stored at refrigerated temperatures for about 42 days and platelet concentrations (PCs) at a temperature range of $20-24^{\circ} \mathrm{C}$ for 5 days. However, stored $\mathrm{RBCs}$ have a reduced $\mathrm{O}_{2}$-binding capacity due to depletion of 2,3-diphosphoglycerate (2,3 DPG) and adenosine tri-phosphate (ATP) [2]. During storage, they can undergo a structural change with loss of deformability and increased osmotic fragility, and also experience an increase in the level of free hemoglobin. Hence, once transfused, they might increase the risks of thrombosis and infection [8,9]. Recently, Koch et al. [10] found that older age of stored RBCs was associated with decreased survival in patients who underwent cardiac surgery.

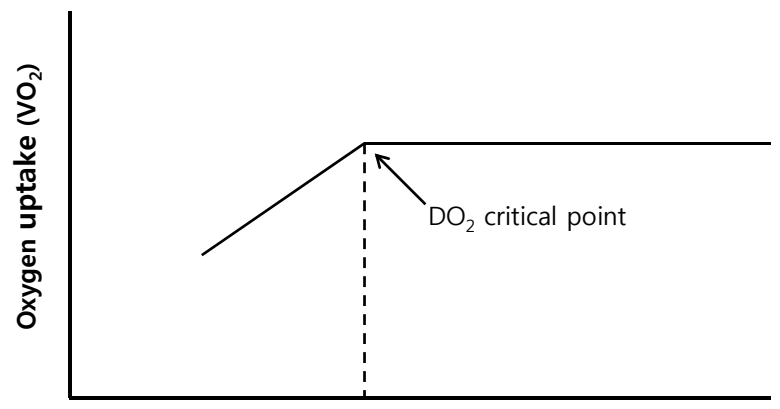

Oxygen delivery $\left(\mathrm{DO}_{2}\right)$

Figure 1. Relationship between oxygen uptake $\left(\mathrm{VO}_{2}\right)$ and oxygen delivery $\left(\mathrm{DO}_{2}\right)$. Oxygen uptake remains stable until oxygen delivery falls below the critical point.

\section{Impact of RBC Transfusion on Oxygen -}

The aim of RBC transfusion is to increase $\mathrm{DO}_{2}$. In a study by Schmidt et al. [11], the authors showed an increased $\mathrm{DO}_{2}$ in patients on ECMO who were transfused with RBCs. However, many animal studies have shown that $\mathrm{VO}_{2}$ remains independent of $\mathrm{DO}_{2}$ over a broad range of values, because oxygen extraction $\left(\mathrm{VO}_{2} / \mathrm{DO}_{2}\right)$ can adapt to a decrease in $\mathrm{DO}_{2}$ as a homeostatic mechanism [6]. Therefore, even when cardiac output is reduced by acute bleeding or hypoxemia, $\mathrm{VO}_{2}$ can remain stable until $\mathrm{DO}_{2}$ falls below a critical point (Figure 1), and patients rarely need RBC transfusions unless they have hemorrhagic shock or severe anemia. Therefore, physicians need to focus on patients' volume status, cardiopulmonary parameters, and the duration and extent of anemia, rather than exclusively on the hemoglobin level as a transfusion trigger. It might also 
be reasonable to develop a parameter reflecting $\mathrm{VO}_{2} / \mathrm{DO}_{2}$ for use as an ideal transfusion threshold $[6,12]$.

\section{General Recommendations for Transfu- sion in Critically III Patients}

A landmark study by the Canadian Critical Care Trial Group [4] demonstrated that a restrictive strategy, using a hemoglobin level of 7.0-9.0 g/dL to trigger RBC transfusion, was as effective as or superior to a liberal transfusion strategy (using hemoglobin level 10.0-12.0 g/dL). The Transfusion Trigger Trial for Functional Outcomes in Cardiovascular Patients Undergoing Surgical Hip Fracture Repair (FOCUS) [13] also showed no benefit of a liberal transfusion strategy in hip surgery patients with a history of, or a risk factor for, cardiovascular disease. Regarding patients with septic shock, European investigators compared lower and higher hemoglobin thresholds (Transfusion Requirements in Septic Shock [TRISS] trial) and reported that patients who were transfused at a hemoglobin threshold of $7 \mathrm{~g} / \mathrm{dL}$, as compared to those transfused at a hemoglobin threshold of $9 \mathrm{~g} / \mathrm{dL}$, received fewer transfusions and had similar rates of 90day mortality and ischemic events [5]. Although some authors recently reported data against restrictive transfusion strategies [14], a meta-analysis by Holst et al. [15] showed that restrictive transfusion strategies were associated with a reduction in the number of RBCs transfused and percent of patients transfused, without increasing mortality or ischemic events. Therefore, taken together, restrictive transfusion strategies are more likely to be beneficial than liberal strategies in critically ill patients, and at present, a low hemoglobin target (i.e., $7 \mathrm{~g} / \mathrm{dL}$ ) is recommended to be used for transfusion threshold.

\section{Blood Transfusions When Old ECMO Sys- tems Were Used}

Older ECMO systems used a roller pump and a long and non-biocompatible (non-heparin-coated) circuit [16]. The system required a priming volume of more than 2 liters and frequent ECMO circuit changes [17]. These factors increased activation of the coagulation system and bleeding complications [18], and were associated with high transfusion volumes. In particular, adult patients on ECMO, compared to neonates or children, required a higher volume of transfusions and therefore, it imposed a considerable burden on hospital blood banks $[19,20]$.

In a study by Butch et al. [19], the daily transfusion units of packed RBCs, PCs, and fresh frozen plasma for ECMO patients were 3.2, 13.6, and 0.1 units, respectively. The study found that about $80 \%$ of transfusion volumes were given during ECMO treatment, and PCs accounted for the largest portion of transfusions. Tolksdorf et al. [17] also reported that packed RBCs of 6.8 units were transfused within the first 24 hours after ECMO system changes in the absence of an autotransfusion device. In the early period of ECMO use, the ECMO system was primed with blood, and the target ranges for hemoglobin (> $14 \mathrm{~g} / \mathrm{dL}$ ) and anticoagulation levels (activated clotting time [ACT], 180-220 seconds) were high $[19,21,22]$. Hence, the transfusion requirement was substantial. However, in present-day practice, crystalloids $(<1$ liter) are used for priming, and the use of heparincoated biocompatible circuits, small-sized oxygenators, and short-length circuits decrease bleeding complications and the need for transfusion.

\section{Current Transfusion Practice in ECMO Patients}

Transfusion requirements are greater among adult patients receiving ECMO than neonates or children receiving ECMO because of the larger size and longer duration of ECMO among adults [23]. Currently, the ELSO guidelines recommend maintaining hemoglobin levels between 12 and $14 \mathrm{~g} / \mathrm{dL}$, and platelet counts at $>75,000 / \mathrm{mm}^{3}$ [1]. The guidelines also advise maintaining $\mathrm{SaO}_{2}$ and $\mathrm{SvO}_{2}$ above $95 \%$ and $75 \%$, respectively, in patients receiving venoarterial (VA) ECMO, and above $80 \%$ and $70 \%$ in 
patients receiving venovenous (VV) ECMO.

Chevuru et al. [24] reported that neonates on ECMO who had sepsis or meconium aspiration required more platelet transfusions (1.9 units/day) than neonates with other conditions, and that there was a significant association between daily number of platelet transfusions and type of ECMO (VA vs. VV vs. VA/VV). VV ECMO patients were shown to have the lowest transfusion requirement. In a study by Henríquez-Henríquez et al. [25], the authors noted that pediatric patients undergoing ECMO due to cardiac disease or congenital diaphragmatic hernia received more transfusions than those undergoing ECMO due to respiratory disease. In their study $(n=98$; VA ECMO, 91\%), 0.98 units/day and 2.1 units/day of RBCs and platelets, respectively, were transfused during the mean 9.2 ECMO days.

In a study on adult ECMO patients by Omar at al. (n = 154; ECMO duration, 5 days; VA ECMO, 82\%) [26], 5 units of RBCs and 9 units of platelets were transfused per day. Ang et al. [23] also investigated 41 adult ECMO patients of whom $83 \%$ received VA ECMO, and reported that, on average, patients were transfused with 2 units of RBCs and 3 units of platelets daily. Interestingly, they recognized that $55 \%$ of patients were transfused with $>10$ packed RBC units, and hemoglobin and platelet counts reached nadir on ECMO day 3.

Compared to patients receiving VA ECMO for cardiac failure, those receiving VV ECMO for respiratory failure tend to need less transfusion volume. In the $2009 \mathrm{H}_{1} \mathrm{~N}_{1}$ pandemic era, the Australia and New Zealand Extracorporeal Membrane Organization Influenza investigators [27] transfused patients with acute respiratory distress syndrome (ARDS) with $188 \mathrm{~mL}$ (0.75 units/day) of RBCs per patient, most of whom were on VV ECMO $(63 / 68)$. In a study by the Italian ECMO network on patients with influenza ARDS, the average volume of RBCs transfused was $1,500 \mathrm{~mL}(400-2,990 \mathrm{~mL})$ per patient (i.e., 0.6 units/day) during the 10 ECMO days [28].

\section{Evidence for Less Transfusion in ECMO Patients}

Smith et al. [29] reported that among 484 infants or children (cardiac ECMO 40\%, non-cardiac ECMO $42 \%$, and extracorporeal cardiopulmonary resuscitation [ECPR], 18\%), transfusion volume was the largest among patients undergoing cardiac ECMO, followed by those on ECPR; nonsurvivors received more transfusions than survivors. Also, in a study by Omar et al. [26], the transfusion volume (RBCs and platelets) was higher in non-survivors compared to survivors.

Recently, two retrospective observational studies were published on restrictive transfusion strategies [30,31]. In a German study of 18 patients with severe ARDS [31], hemoglobin concentrations were maintained between 7.0 and $9.0 \mathrm{~g} / \mathrm{dL}$, and the transfusion trigger was a hemoglobin level $<7.0 \mathrm{~g} / \mathrm{dL}$. Their results showed that the mean hemoglobin level and hematocrit were $8.3 \mathrm{~g} / \mathrm{dL}$ and $25.0 \%$ during ECMO, which were lower than the levels found in influenza ARDS patients by the Italian ECMO network [28]. They found that overall mortality was $38.9 \%$, but transfusion volume tended to be higher in nonsurvivors than in survivors (1.97 vs. 0.96 units/day, $\mathrm{p}=0.07)$. In another study, Agerstrand et al. [30] used a blood conservation strategy for 38 ARDS patients, which was comprised of a low transfusion trigger (hemoglobin level $<7.0 \mathrm{~g} / \mathrm{dL}$ ), a low activated partial thromboplastin time (aPTT) target (40-60 seconds), and use of autotransfusion. Their survival rate was $73.7 \%$ and the transfusion rate was $63.2 \%$. They increased the ECMO flow rate, instead of transfusing RBCs, to keep $\mathrm{SpO}_{2}>92 \%$. On average, a total of 1 packed RBC unit/patient was transfused during ECMO (0.11 units/day/patient), which was lower than previously reported rates. They also noted that rates of thrombosis and bleeding complications were not remarkable, and that number of transfusions, rather than baseline hemoglobin levels, were associated with higher mortality [30].

Regarding fluid management, we are aware of a study that compares two-fluid management strategies in pa- 
tients with acute lung injury, published in 2006 by the ARDS Clinical Trial Network [32]. The study provided strong evidence for the beneficial effects of conservative fluid management on patients with lung injury. This is relevant to patients undergoing ECMO, for whom blood transfusions are considered. ELSO guidelines also recommend that diuretics be used until dry weight is achieved. However, it is worth considering that the transfusion (or fluid) strategy in patients undergoing ECMO for respiratory failure could be different from those undergoing ECMO for cardiac failure [33].

\section{Other Strategies for Reducing Transfu- sion Volume}

RBC transfusions during ECMO system change $(\sim 2.5$ liters) can induce acute volume overload, activate the coagulation system, and cause an inflammatory reaction. Tolksdorf et al. [17] performed autotransfusion in 7 patients on ECMO, and it reduced RBC transfusion volume from 6.8 to 1.9 units. The advantages of autologous transfusion are a lower humoral immune response, lower infection risk, and shorter length of hospital stay. In particular, the authors found that the depletion of leukocytes and platelets using cell saver, in contrast to whole blood out of heart-lung machines in cardiac surgery, can reduce inflammatory response and improve lung function after transfusion. Also, in a study by Agerstrand et al. [30], autotransfusion during decannulation was included in their blood conservation protocol.

The duration of ECMO was associated with volume of transfusion and a tendency towards decreased platelet count. Hence, it is recommended to attempt to shorten the duration of ECMO [23,34]. Furthermore, minimizing daily samplings could be regarded as a strategy for fewer blood transfusions [30,34], and some authors have emphasized the importance of standardized transfusion protocol and education of medical personnel [30,34]. Although feasible in clinical practice, they need to be further investigated in the future.

\section{Conclusions}

To date, most knowledge on transfusion strategies was extrapolated from studies in critically ill patients; evidence for patients undergoing ECMO is limited. However, recent improvements in ECMO technology decreased the need of blood transfusions and current data support a restrictive transfusion strategy for ECMO patients. A low transfusion trigger (hemoglobin $<7.0 \mathrm{~g} / \mathrm{dL}$ ), a low anticoagulation target (aPTT 40-60 seconds), minimizing phlebotomy, and if possible, autotransfusion during decannulation, are likely to be associated with decreased transfusion volume in clinical practice. Reducing ECMO duration may also be beneficial. However, importantly, physicians need to take various patients' conditions into consideration, not focusing exclusively on the hemoglobin level as a transfusion trigger. In the future, welldesigned randomized controlled studies are needed to prove the benefits of the strategies mentioned above in ECMO patients.

\section{ORCID}

Hyoung Soo Kim http://orcid.org/0000-0001-6023-0818

Sunghoon Park http://orcid.org/0000-0001-7004-6985

\section{References}

1. Extracorporeal Life Support Organization (ELSO). ELSO guidelines [Internet]. Ann Arbor, ELSO, c2016. [cited 2016 Oct 30]. Available from: https:// www.elso.org/Resources/Guidelines.aspx.

2. Holst LB. Benefits and harms of red blood cell transfusions in patients with septic shock in the intensive care unit. Dan Med J 2016; 63: B5209.

3. Gilliss BM, Looney MR, Gropper MA. Reducing noninfectious risks of blood transfusion. Anesthesiology 2011; 115: 635-49.

4. Hébert PC, Wells G, Blajchman MA, Marshall J, 
Martin C, Pagliarello G, et al. A multicenter, randomized, controlled clinical trial of transfusion requirements in critical care. Transfusion Requirements in Critical Care Investigators, Canadian Critical Care Trials Group. N Engl J Med 1999; 340: 409-17.

5. Holst LB, Haase N, Wetterslev J, Wernerman J, Guttormsen $\mathrm{AB}$, Karlsson $\mathrm{S}$, et al. Lower versus higher hemoglobin threshold for transfusion in septic shock. N Engl J Med 2014; 371: 1381-91.

6. Roberson RS, Bennett-Guerrero E. Impact of red blood cell transfusion on global and regional measures of oxygenation. Mt Sinai J Med 2012; 79: 66-74.

7. Kiefel V. Reactions induced by platelet transfusions. Transfus Med Hemother 2008; 35: 354-8.

8. Lelubre C, Vincent J. Red blood cell transfusion in the critically ill patient. Ann Intensive Care 2011; 1: 43.

9. Tinmouth A, Fergusson D, Yee IC, Hébert PC; ABLE Investigators; Canadian Critical Care Trials Group. Clinical consequences of red cell storage in the critically ill. Transfusion 2006; 46: 2014-27.

10. Koch CG, Li L, Sessler DI, Figueroa P, Hoeltge GA, Mihaljevic T, et al. Duration of red-cell storage and complications after cardiac surgery. N Engl J Med 2008; 358: 1229-39.

11. Schmidt M, Tachon G, Devilliers C, Muller G, Hekimian $\mathrm{G}$, Bréchot $\mathrm{N}$, et al. Blood oxygenation and decarboxylation determinants during venovenous ECMO for respiratory failure in adults. Intensive Care Med 2013; 39: 838-46.

12. Marik PE, Flemmer M, Shander A. Liberal or restrictive transfusion after cardiac surgery. N Engl J Med 2015; 373: 190-1.

13. Carson JL, Terrin ML, Noveck H, Sanders DW, Chaitman BR, Rhoads GG, et al; FOCUS Investigators. Liberal or restrictive transfusion in high-risk patients after hip surgery. N Engl J Med 2011; 365: 2453-62.

14. Murphy GJ, Pike K, Rogers CA, Wordsworth S, Stokes EA, Angelini GD, et al. TITRe2 Investigators: Liberal or restrictive transfusion after cardiac surgery. N Engl J Med 2015; 372: 997-1008.
15. Holst LB, Petersen MW, Haase N, Perner A, Wetterslev J. Restrictive versus liberal transfusion strategy for red blood cell transfusion: systematic review of randomised trials with meta-analysis and trial sequential analysis. BMJ 2015; 350: h1354.

16. Joshi V, Harvey C, Nakas A, Waller DA, Peek GJ, Fir$\min \mathrm{R}$. The need for thoracic surgery in adult patients receiving extracorporeal membrane oxygenation: a 16-year experience. Perfusion 2013; 28: 328-32.

17. Tolksdorf B, Schmeck J, Osika A, Bender HJ, Quintel M. Autotransfusion during extracorporeal membrane oxygenation. Int J Artif Organs 2000; 23: 840-4.

18. Arnold P, Jackson S, Wallis J, Smith J, Bolton D, Haynes S. Coagulation factor activity during neonatal extra-corporeal membrane oxygenation. Intensive Care Med 2001; 27: 1395-400.

19. Butch SH, Knafl P, Oberman HA, Bartlett RH. Blood utilization in adult patients undergoing extracorporeal membrane oxygenated therapy. Transfusion 1996; 36: 61-3.

20. McCoy-Pardington D, Judd WJ, Knafl P, Abruzzo LV, Coombes KR, Butch SH, et al. Blood use during extracorporeal membrane oxygenation. Transfusion 1990; 30: 307-9.

21. Morris AH, Wallace CJ, Menlove RL, Clemmer TP, Orme JF Jr, Weaver LK, et al. Randomized clinical trial of pressure-controlled inverse ratio ventilation and extracorporeal $\mathrm{CO} 2$ removal for adult respiratory distress syndrome. Am J Respir Crit Care Med 1994; 149(2 Pt 1): 295-305.

22. Peek GJ, Moore HM, Moore N, Sosnowski AW, Firmin RK. Extracorporeal membrane oxygenation for adult respiratory failure. Chest 1997; 112: 759-64.

23. Ang AL, Teo D, Lim CH, Leou KK, Tien SL, Koh MB. Blood transfusion requirements and independent predictors of increased transfusion requirements among adult patients on extracorporeal membrane oxygenation -- a single centre experience. Vox Sang 2009; 96: 34-43.

24. Chevuru SC, Sola MC, Theriaque DW, Hutson AD, Leung WC, Perez JA, et al. Florida Collaborative 
Neonatology Research Group: multicenter analysis of platelet transfusion usage among neonates on extracorporeal membrane oxygenation. Pediatrics 2002; 109: e89.

25. Henríquez-Henríquez M, Kattan J, Chang M, Pizarro I, Faunes M, Martinez C, et al. Blood component usage during extracorporeal membrane oxygenation: experience in 98 patients at a Latin-American tertiary hospital. Int J Artif Organs 2014; 37: 233-40.

26. Omar HR, Mirsaeidi M, Socias S, Sprenker C, Caldeira C, Camporesi EM, et al. Plasma free hemoglobin is an independent predictor of mortality among patients on extracorporeal membrane oxygenation support. PLoS One 2015; 10: e0124034.

27. Australia, New Zealand Extracorporeal Membrane Oxygenation (ANZ ECMO) Influenza Investigators, Davies A, Jones D, Bailey M, Beca J, Bellomo R, et al. Extracorporeal membrane oxygenation for 2009 influenza $\mathrm{A}(\mathrm{H} 1 \mathrm{~N} 1)$ acute respiratory distress syndrome. JAMA 2009; 302: 1888-95.

28. Patroniti N, Zangrillo A, Pappalardo F, Peris A, Cianchi G, Braschi A, et al. The Italian ECMO network experience during the 2009 influenza A(H1N1) pandemic: preparation for severe respiratory emergency outbreaks. Intensive Care Med 2011; 37: 1447-57.

29. Smith A, Hardison D, Bridges B, Pietsch J. Red blood cell transfusion volume and mortality among patients receiving extracorporeal membrane oxygenation. Perfusion 2013; 28: 54-60.

30. Agerstrand CL, Burkart KM, Abrams DC, Bacchetta MD, Brodie D. Blood conservation in extracorporeal membrane oxygenation for acute respiratory distress syndrome. Ann Thorac Surg 2015; 99: 590-5.

31. Voelker MT, Busch T, Bercker S, Fichtner F, Kaisers UX, Laudi S. Restrictive transfusion practice during extracorporeal membrane oxygenation therapy for severe acute respiratory distress syndrome. Artif Organs 2015; 39: 374-8.

32. National Heart Lung, and Blood Institute Acute Respiratory Distress Syndrome (ARDS) Clinical Trials Network, Wiedemann HP, Wheeler AP, Bernard GR, Thompson BT, Hayden D, et al. Comparison of two fluid-management strategies in acute lung injury. $\mathrm{N}$ Engl J Med 2006; 354: 2564-75.

33. Brodie D, Bacchetta M. Extracorporeal membrane oxygenation for ARDS in adults. N Engl J Med 2011; 365: 1905-14.

34. Rosenberg EM, Chambers LA, Gunter JM, Good JA. A program to limit donor exposures to neonates undergoing extracorporeal membrane oxygenation. Pediatrics 1994; 94: 341-6. 